Research Paper

\title{
Fetal Hypoxia Results in Programming of Aberrant An- giotensin II Receptor Expression Patterns and Kidney Development
}

\author{
Pablo Jr. Gonzalez-Rodriguez, Wenni Tong, Qin Xue, Yong Li, Shirley Hu and Lubo Zhang ${ }^{\bowtie}$ \\ Center for Perinatal Biology, Division of Pharmacology, Department of Basic Sciences, Loma Linda University School of Medicine, Loma \\ Linda, CA, 92350, USA. \\ $\triangle$ Corresponding author: Lubo Zhang, Ph.D. Center for Perinatal Biology, Division of Pharmacology, Department of Basic Sciences, Loma \\ Linda University School of Medicine, Loma Linda, CA 92350. Tel: (909) 558-4325 Fax: (909) 558-4029 Email: lzhang@llu.edu.
}

() Ivyspring International Publisher. This is an open-access article distributed under the terms of the Creative Commons License (http://creativecommons.org/ licenses/by-nc-nd/3.0/). Reproduction is permitted for personal, noncommercial use, provided that the article is in whole, unmodified, and properly cited.

Received: 2012.II.I9; Accepted: 2013.02.26; Published: 2013.03.13

\begin{abstract}
AIMS: The present study tested the hypothesis that fetal hypoxia adversely affects kidney development in fetal and offspring rats and alter the expression patterns of angiotensin II type I $\left(A T_{1} R\right)$ and type $2\left(A T_{2} R\right)$ receptors.

METHODS: Time-dated pregnant rats were divided between normoxic and hypoxic $\left(10.5 \% \mathrm{O}_{2}\right.$ last period of gestation) groups. Protein expression, in the offspring, was determined using western blot.

RESULTS: Hypoxic treatment significantly decreased body and kidney weight in $2 \mathrm{I}$-day fetuses (E2I) and 7-day neonates (P7). In 3-month-old offspring there were no significant differences in body and kidney weight between hypoxic and control animals. Fetal hypoxia had no effect on kidney $A T_{1} R$ density in E2I or P7, but significantly decreased kidney $A T_{1} R$ protein and mRNA abundance in both male and female adults. In contrast, kidney $A T_{2} R$ density was not affected by fetal hypoxia throughout the developmental stages studied. The hypoxia-mediated reduction of nephron numbers was progressively from P7 worsened into the adulthood with females affected more than males.

CONCLUSION: The results suggest that fetal hypoxia causes programming of aberrant kidney development and accelerates the aging process of the kidney during the postnatal development, which may contribute to an increased risk of cardiovascular disease.
\end{abstract}

Key words: Rats, $\mathrm{AT}_{1} \mathrm{R}, \mathrm{AT}_{2} \mathrm{R}$, nephron number, sex.

\section{Introduction}

The most critical period of the human being is during fetal development, the stage in which the mother could expose the fetus to adverse environment that could have a long-term effect during adulthood. The studies of Barker and colleagues are the fundament for what is known as developmental programming of diseases, in which they found an inverse relationship between birth weight and cardiovascular diseases later in the adulthood 1,2. Two of the most common challenges to the fetus during de- velopment are reduction in oxygen and nutrient delivery. There are various maternal stressors that could affect body weight in the offspring, for example maternal protein-restriction diet 3 , nicotine exposure ${ }^{4}$, intrauterine malnutrition ${ }^{5}$, and hypoxia ${ }^{6}$.

Retardation of renal development that occurs in individuals of low birth weight increases the risk of renal diseases during adulthood 7 . The process of nephrogenesis in the rats starts during mid-gestation and finishes by post-natal day $14^{8}$. Previous studies 
demonstrated that maternal low-protein diet in rats resulted in low birth weight, suppressed the renal renin-angiotensin system (RAS), and reduced the number of nephrons, leading to hypertension in offspring ${ }^{9}$. The aging process of the kidney is associated with physiological and functional changes, including reduced kidney weight and glomerular number, and changes in the shape of glomeruli and the formation of glomerular arterioles ${ }^{10}$. These changes in combination with decrease in renal function lead to hypertension and other cardiovascular diseases. The RAS is associated with one of the mechanisms that are involved in developmental problems in fetal organs, including the kidney ${ }^{11}$. Angiotensin II is the primary peptide in the system, which activates two subtypes of G-protein coupled receptors: angiotensin II type 1 $\left(\mathrm{AT}_{1} \mathrm{R}\right)$ and type $2\left(\mathrm{AT}_{2} \mathrm{R}\right)$ receptors. The $\mathrm{AT}_{1} \mathrm{R}$ plays a key role in the regulation of blood pressure, hormone secretion and renal function while $\mathrm{AT}_{2} \mathrm{R}$ is involved mainly in the development and growth ${ }^{12}$.

Little is known about the effect of common fetal stress of hypoxia on the kidney development. Therefore, in the present study, we determined the effect of fetal hypoxia on the glomerular development and the expression patterns of $\mathrm{AT}_{1} \mathrm{R}$ and $\mathrm{AT}_{2} \mathrm{R}$ in the kidney in three developmental stages of near-term fetal, neonatal, and adult rats. The results suggest that fetal hypoxia causes programming of aberrant kidney development and accelerates the aging process of the kidney during the postnatal development, which may contribute to an increased risk of cardiovascular disease, particularly hypertension in offspring.

\section{Material and Methods}

Experimental Animals and Hypoxic Exposure. Time-dated pregnant Sprague-Dawley rats were purchased from Charles River Laboratories (Portage, $\mathrm{MI})$ and were randomly divided into normoxic control group and continuous hypoxic exposure group. The hypoxic group was exposed to $10.5 \%$ oxygen from day 15 to day 21 of gestation, a period comparable with the third trimester of gestation in humans. Hypoxia was induced to the pregnant rats by a mixture of nitrogen gas and air in individual chambers as described previously ${ }^{13}$. The normoxic control group was housed identically with room air flowing through chambers. Water and food were provided as desired. Some of the pregnant rats, of both groups, were allowed to give birth naturally, and no fetal loss in the normoxia or hypoxia groups was observed. The offspring were allowed to lactation and no further treatment before euthanasia at postnatal day 7 (P7) and 3 month-old $(3 \mathrm{M})$. The other pregnant dams were sacrificed on day 21 of gestation and fetuses (E21) were collected for studies. Kidneys were isolated and stored at $-80^{\circ} \mathrm{C}$. Body and kidney weight was determined. All procedures and protocols used in the present study were approved by the Institutional Animal Care and Use Committee of Loma Linda University and followed the guidelines in the National Institutes of Health Guide for the Care and Use of Laboratory Animals.

Immunoblotting. Protein abundance of renal $\mathrm{AT}_{1} \mathrm{R}$ and $\mathrm{AT}_{2} \mathrm{R}$ was determined with Western blot analysis as reported previously ${ }^{14}$. Briefly, kidneys were homogenized in an ice-cold lysis buffer (20 mM HEPES, $10 \mathrm{mM} \mathrm{KCl}, 1.5 \mathrm{mM} \mathrm{MgCl} 2,1 \mathrm{mM}$ EDTA, $1 \mathrm{mM}$ EGTA, $1 \mathrm{mM}$ dithiothreitol, $1 \mathrm{mM}$ phenylmethylsulfonyl fluoride and $2 \mu \mathrm{g} / \mathrm{ml}$ aprotinin, $\mathrm{pH}$ 7.4). Homogenates were centrifuged at $4^{\circ} \mathrm{C}$ for $10 \mathrm{~min}$ at $14,000 \mathrm{~g}$, and supernatants aliquots were collected and stored at $-80^{\circ} \mathrm{C}$. Protein concentrations were determined using a protein assay kit from Bio-Rad. Samples with equal protein $(40 \mu \mathrm{g})$ were loaded on $7.5 \%$ sodium dodecyl sulfate polyacrylamide gel (SDS-PAGE) and performed the electrophoresis analysis. After electrophoresis, proteins were transferred to nitrocellulose membranes. Nonspecific binding was blocked in TBST containing 5\% dry milk for $60 \mathrm{~min}$ at room temperature. The membranes were incubated with rabbit $\mathrm{AT}_{1} \mathrm{R}$ and $\mathrm{AT}_{2} \mathrm{R}$ polyclonal antibody (1:1000 and 1:2000 dilution respectively; Santa Cruz Biotechnology, Santa Cruz, CA) overnight at $4^{\circ} \mathrm{C}$. The membranes were then washed and incubated with secondary horseradish peroxidase-conjugated goat anti-rabbit antibody (1:4000 dilution; Santa Cruz Biotechnology, Santa Cruz, CA). Protein bands were visualized with enhanced chemiluminescence reagents, and the blots were exposed to Hyperfilm (GE Healthcare). Results were analyzed and quantified by the Kodak electrophoresis documentation and analysis system with Kodak ID image analysis software. For comparison of the levels of $\mathrm{AT}_{1} \mathrm{R}$ and $\mathrm{AT}_{2} \mathrm{R}$ protein relative density between the groups, samples were normalized first to GAPDH values and then presented as fold values relative to control animals.

$R T-P C R$. RNA was isolated from kidneys of adult offspring using TRIzol reagents (Invitrogen, Carlsbad, CA, USA) and was subjected to reverse transcription with Superscript III First-Strand Synthesis System (Invitrogen), following the manufacturer's instructions. Briefly, $5 \mu \mathrm{g}$ total RNA was reverse transcribed into cDNA in a $20 \mu \mathrm{l}$ volume reaction following the protocol of $50^{\circ} \mathrm{C}$ for $50 \mathrm{~min}$ and $85^{\circ} \mathrm{C}$ for $5 \mathrm{~min}$. The mRNA abundance of $\mathrm{AT}_{1 \mathrm{a}} \mathrm{R}$ and $\mathrm{AT}_{1 b} \mathrm{R}$ was measured with real-time PCR using $\mathrm{iQ}$ SYBR Green Supermix (Bio-Rad, Hercules, CA, USA). GAPDH was used as internal reference. Primers used for $\mathrm{AT}_{1 \mathrm{a}} \mathrm{R}$ : 5'-ccattcaccetgcctcag-3' (forward) and 
$5^{\prime}$-acggctttgcttggttactc-3' (reverse) and for $\mathrm{AT}_{1 \mathrm{~b}} \mathrm{R}$ : 5'-atgtctccagtcccctctca-3' (forward) and 5'-tgacctcccatc tccttttg-3' (reverse). Real-time PCR was performed in a final volume of $25 \mu \mathrm{l}$ and each PCR reaction mixture consisted of $500 \mathrm{nM}$ of primers and iQ SYBR Green Supermix containing 0.625 unit hot-start Taq polymerase, $400 \mu \mathrm{M}$ each of dATP, dCTP, dGTP, and dTTP, $100 \mathrm{mM} \mathrm{KCl}, 16.6 \mathrm{mM}$ ammonium sulfate, 40 $\mathrm{mM}$ Tris- $\mathrm{HCl}, 6 \mathrm{mM} \mathrm{MgSO}$, SYBR Green I, $20 \mathrm{nM}$ fluorescing and stabilizers. We used the following real time-PCR protocol: $95^{\circ} \mathrm{C}$ for $10 \mathrm{~min}$, followed by 40 cycles of $95^{\circ} \mathrm{C}$ for $10 \mathrm{~s}$, annealing for $10 \mathrm{~s}$ at appropriate temperature depending on the primer sequence, $72^{\circ} \mathrm{C}$ for $10 \mathrm{~s}$. Serial dilutions of the positive control were done on each plate to create a standard curve for the quantification.

Glomerular counting. The number of glomeruli per kidney was determined for P7 and $3 \mathrm{M}$ female and male rats as previously described ${ }^{15}$. Briefly, kidneys were removed and weighed. Whole kidneys were incubated in $50 \%$ hydrochloric acid for $45 \mathrm{~min}$ at $37^{\circ} \mathrm{C}$, the incubation time being dependent on kidney weight. Kidneys were rinsed with tap water and stored overnight at $4^{\circ} \mathrm{C}$ in a gauged flask. Following mechanical dissociation, tubules and glomeruli were suspended in $10 \mathrm{ml}$ of distilled water. Three $0.5-\mathrm{ml}$ aliquots were obtained from each kidney homogenate
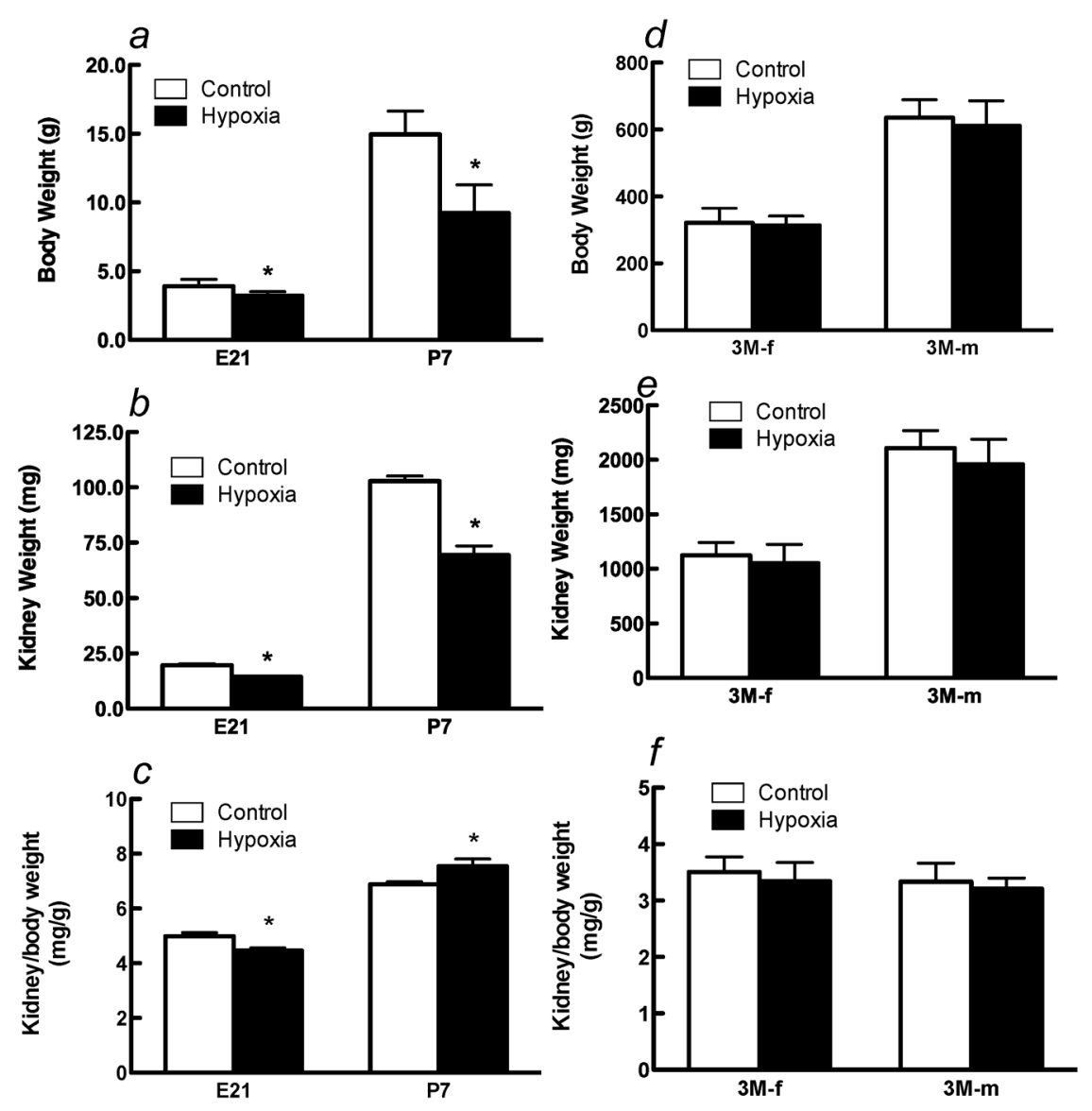

and placed in a hemocytometer-like chamber, and glomeruli were counted under microscope by two investigators who were unaware of the specimen origin. The three results were averaged, and then the value was used to determine the total number of glomeruli in the sample and therefore in the kidney.

Statistical analysis. Results are expressed as mean \pm standard error of mean (SEM). Experimental number $(\mathrm{N})$ represents fetuses and offspring from different dams. Statistical comparisons for the body and kidney weight, the kidney to body weight ratio, and the number of glomeruli were conducted by two-way ANOVA followed by a Bonferroni test. Differences in $A T_{1} R$ or $A_{2} R$ protein abundance between normoxic and hypoxic groups were compared using unpaired t-test analysis. In all cases the differences were considered significant when $P<0.05$.

\section{Results}

Effects of fetal hypoxia on body and kidney weight. Fetal hypoxia resulted in a significant decrease in body and kidney weight in E21 and P7 rats (Figure 1A, 1B). The kidney-to-body weight ratio was significantly higher in P7 rats than that in E21 rats (Figure $1 C)$, indicating a continuous growth and maturation of the kidney in neonatal rats. Hypoxia treatment decreased the kidney-to-body weight ratio in E21 rats but increased it in P7 rats (Figure 1C). In $3 \mathrm{M}$ offspring, there were no significant differences in body and kidney weight in either males or females between the control and hypoxic-treated animals (Figures $1 \mathrm{D}$ and 1E). The kidney-to-body weight ratio was not significantly different between males and females in adult offspring, but both were significantly decreased as compared with that in P7 neonates (Figures $1 \mathrm{C}$ and $1 \mathrm{~F}$ ). Fetal hypoxia had no significant effect on the kidney-to-body weight ratio in either male or female adult offspring (Figure 1F).

Figure I. Effect of maternal hypoxia exposure on body weight (a), kidney weight (b) and in the kidney/body weight ratio (c) in fetus of embryonic day 2I (E2I) and post-natal day 7 (P7) offspring and on body weight (d), kidney weight (e) and in the kidney/body weight ratio (f) in 3 month-old females (3M-f) and 3 month-old males (3M-m) offspring. $* \mathrm{P}<0.05 ; \mathrm{N}=12$. 
Effects of fetal hypoxia on renal $A T_{1} R$ and $A T_{2} R$ protein and $m R N A$ abundance. The protein abundance of $\mathrm{AT}_{1} \mathrm{R}$ and $\mathrm{AT}_{2} \mathrm{R}$ in the kidney was determined by Western blot analysis. As shown in figure 2, $\mathrm{AT}_{1} \mathrm{R}$ protein abundance in the kidney was not significantly different in either fetal or neonatal rats between the control and hypoxic-treated animals. However, in adult offspring, $\mathrm{AT}_{1} \mathrm{R}$ protein abundance in the kidney was significantly decreased in both males $(43 \%)$ and females (62\%) that had exposed to hypoxia before birth, as compared with the control animals (Figure 2). Consistent with the decreased $\mathrm{AT}_{1} \mathrm{R}$ protein abundance, fetal hypoxia resulted in a significant decrease in mRNA abundance of $\mathrm{AT}_{1 \mathrm{a}} \mathrm{R}$ and $\mathrm{AT}_{1 \mathrm{~b}} \mathrm{R}$ in the kidney of both male and female offspring (Figure 3 ). In contrast, fetal hypoxia had no significant effect on $\mathrm{AT}_{2} \mathrm{R}$ protein abundance in the kidney at all three developmental stages examined (Figure 4). Thus, prenatal hypoxia significantly decreased the $\mathrm{AT}_{1} \mathrm{R}$ to $\mathrm{AT}_{2} \mathrm{R}$ ratio in the kidney of adult offspring (Figure 5).

Effects of fetal hypoxia on glomerular number. Figure 6 shows the effect of fetal hypoxia on total number of glomeruli per kidney in neonates and adult offspring. In P7 neonates, there was a small but significant decrease in kidney glomerular numbers in hypoxic-treated animals, as compared with the normoxic pups (Figure 6). This hypoxia-mediated reduction of nephron numbers was progressively worsened into the adulthood with females (52\% reduction) affected more than males (26\% reduction) (Figure 6).
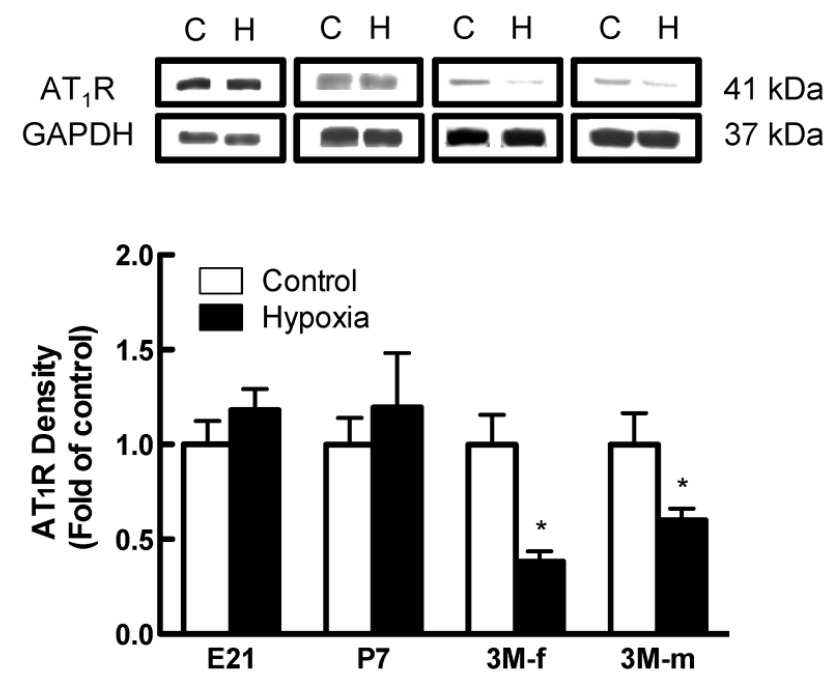

Figure 2. AT,R protein expression on kidney of fetus of embryonic day $2 \mathrm{I}$ (E2I), post-natal day 7 (P7), 3 month-old male $(3 M-m)$ and 3 month-old female (3M-f) after maternal hypoxia and normoxia. Protein levels were determined by Western blots $(C-$ control; $\mathrm{H}-$ hypoxia). $* \mathrm{P}<0.05 ; \mathrm{N}=5$.

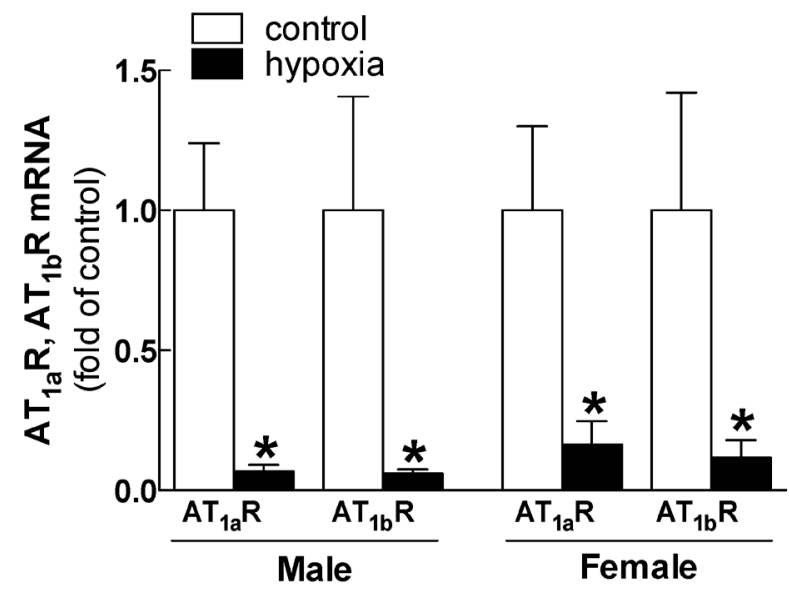

Figure 3. Relative expression of $A T_{1 \mathrm{a}} R$ and $A T_{1 b} R$ mRNA in kidney of male and female adult offspring rats that were exposed to fetal hypoxia during the last week of gestational period. Real-time PCR was performed using tissue from the left kidneys of these animals. $* P<0.05 ; N=5$.

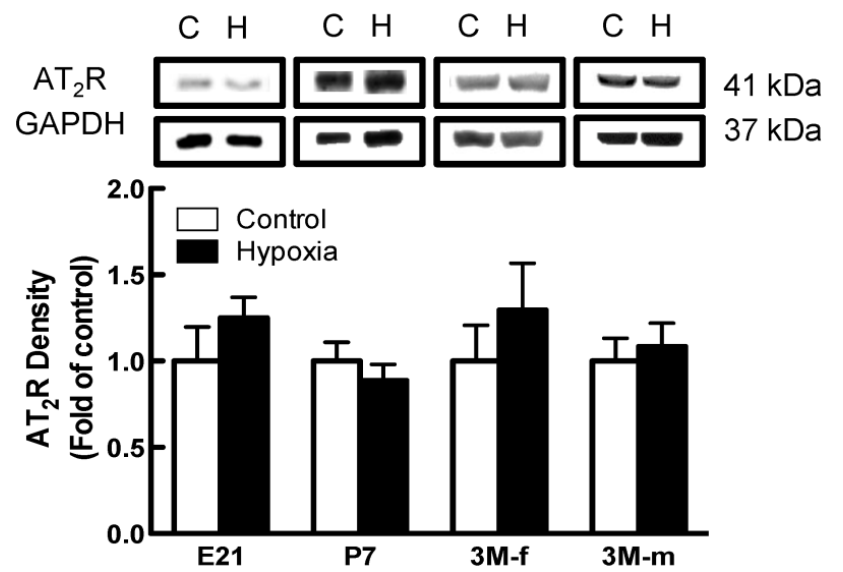

Figure 4. Effect of maternal hypoxia exposure on protein expression of $A T_{2} R$ in the kidney for fetus of embryonic day $2 \mathrm{I}$ (E2I), post-natal day 7 (P7), male and female 3 month-old (3M-f and $3 \mathrm{M}-\mathrm{m})$ offspring. Protein levels were determined by Western blots (C - control; $\mathrm{H}-$ hypoxia). $* \mathrm{P}<0.05 ; \mathrm{N}=5$.

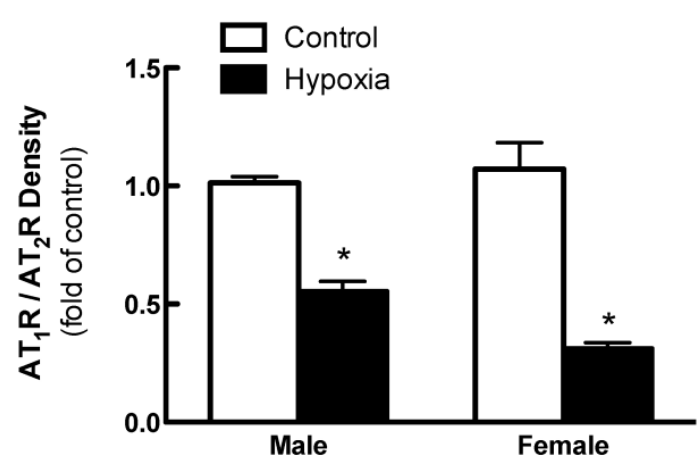

Figure 5. Effect of maternal hypoxia exposure on kidney $A T_{1} R / A T_{2} R$ protein expression ratio in 3 month-old male and female offspring. $* P<0.05 ; N=5$. 


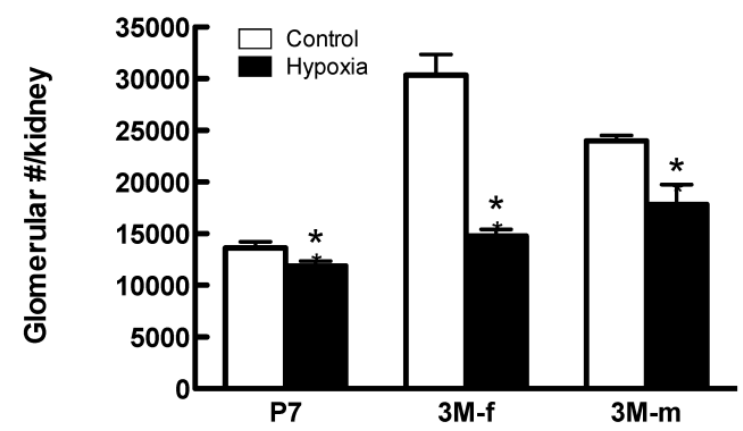

Figure 6. Glomerular number in offspring post-natal day 7 (P7), 3 month-old female (3M-f) and 3 month-old male $(3 M-m)$ of mothers maintained on normoxia throughout pregnancy or exposed to hypoxia during last week of gestation. ${ }^{*} \mathrm{P}<0.05 \mathrm{~N}=5$.

\section{Discussion}

There is plenty of evidence that correlates low birth weight in term gestation with an increased risk of cardiovascular disease during adulthood ${ }^{16}$. The present finding that fetal hypoxia caused a significant decrease in the body weight of fetal and neonatal rats is consistent with the previous studies ${ }^{17}$. No significant difference was observed in the adult offspring between normoxia and hypoxia-treated animals in the present study, suggesting "catch-up" growth during postnatal development in hypoxia-treated animals. A number of studies have shown that in utero undernutrition causes fetal growth restriction and low birth weight, which is associated with "catch-up" growth during postnatal development 18,19 . These studies suggest a common response of decreased body weight in early developmental stage and "catch-up" growth in postnatal development in fetal malnutrition and fetal hypoxia models. It has been shown that low birth weight associated with accelerated postnatal growth is a trigger for development of adult disease and ultimately can affect longevity ${ }^{20}$.

In the present study, fetal hypoxia resulted in a decrease in the kidney weight in the fetus and neonate. However in adult offspring, the kidney weight was not significantly different between the control and hypoxic-treated animals in both females and males. Interesting, perinatal nicotine exposure affected the kidney weight not just in the fetus and neonate but also in female and male adult offspring ${ }^{21}$. The finding that the kidney-to-body weight ratio was significantly greater in P7 rats than that in E21 rats indicates a continuous growth and maturation of the kidney in neonatal rats. This is consistent with the previous finding that the process of nephrogenesis in the rats starts during mid-gestation and finishes by postnatal day $14{ }^{8}$. The finding that the kid- ney-to-body weight ratio was significantly decreased in adult rats as compared with that in neonatal rats is intriguing and suggests asymmetric growth and aging process of reduced kidney weight during the postnatal development ${ }^{11}$. Hypoxia decreased the kidney-to-body weight ratio in E21 rats. It has been demonstrated that fetal hypoxia results in a decrease of amniotic fluid production and redistribution of fetal blood flow with a decrease in perfusion to the kidney and an increase of perfusion to the brain, heart and liver ${ }^{22}$. The finding of the increased kidney-to-body weight ratio in P7 rats in hypoxic animals suggests a compensatory growth of the kidney in neonates. Similar to the present finding, maternal protein restriction caused a decrease in the kidney-to-body weight ratio in the newborn and P1 offspring, but in P5 there was no difference in the ratio between the low protein diet and control groups ${ }^{19}$.

Abnormal development of the kidney may affect adult cardiovascular and renal function. Brenner et al. 23 introduced the hypothesis that due to a lower nephron number the surface area of filtration is smaller, leading to an increase in glomerular pressure and systematic hypertension. There is plenty of evidence regarding the existence of a relationship between lower nephron number and hypertension in humans 24 and in rats ${ }^{25}$. Several different animal models including maternal alcohol administration and high salt diet during pregnancy demonstrated the reduced nephron number and increased blood pressure in adult offspring ${ }^{25}$. Woods et al. reported that the maternal protein restriction decreased the number of nephrons in adult kidneys. Interesting, they found that although the degree of hypertension in male and female adult rats was similar, the number of nephrons in males was lower than that in females ${ }^{19}$. In contrast to the findings in animal models of low protein diet and high salt diet ${ }^{19}$, fetal hypoxia resulted in a greater reduction in the nephron number in female $(52 \%)$ than male $(26 \%)$ adult offspring. These findings suggest differential effects of fetal insults on gender-specific programming of aberrant nephron development. Although it is generally perceived, at least in human, that the number of glomeruli does not change after birth in rats the nephrogenesis starts in mid-gestation and continues up to day 14 neonates. In the present study, hypoxia caused a decrease in glomerular number in P7 neonates and a rest of nephrogenesis, resulting in significantly reduced glomeruli in the adult kidney. Whereas the total glomerular volume was not determined in the present study, the effect of hypoxia on the functional maturation and glomerular volume may not be excluded given that the mean glomerular volume has been shown to be 
programed by fetal stress and has an impact on kidney disease and hypertension 25,26 . The finding that the kidney-to-body weight ratio was not difference in adult rats even though the number of glomeruli is significantly lower for the hypoxia group, may be due to glomerular hypertrophy that help maintain renal filtration surface area. This, however, may in turn lead to adverse effects in the kidney as a result of chronic glomerular hyperfiltration ${ }^{27}$. The reduction of nephron numbers may accelerate the aging process of the kidney and contribute to an increased risk of cardiovascular disease, particularly hypertension in offspring. It has been shown that the aging process of the kidney is associated with reduced glomerular number, which contributes to an increased risk of hypertension and other cardiovascular diseases ${ }^{11}$.

The Renin-Angiotensin System (RAS) is a key regulator of blood pressure, fluid/electrolyte homeostasis, and kidney development 3,28 . A recent study demonstrated that prenatal nicotine exposure did not affect the expression of $\mathrm{AT}_{1} \mathrm{R}$ in rat kidneys of 14-days, 30-days and 3-month offspring, as compared with the control groups ${ }^{21}$. However, the nicotine treatment decreased the expression of $\mathrm{AT}_{2} \mathrm{R}$ in all the three post-natal ages. The present study demonstrated that fetal hypoxia decreased the mRNA and protein expression of $\mathrm{AT}_{1} \mathrm{R}$ in adult offspring but had no effect on $\mathrm{AT}_{2} \mathrm{R}$ expression, suggesting that different maternal stresses affect the organogenesis of the kidney in different manners. Additionally, it has been shown that maternal protein restriction diet suppresses the expression of renal RAS probably due to the reduced number of glomeruli per kidney, which is associated with the increased arterial blood pressure in the adult rats ${ }^{3}$. Using losartan, an antagonist for $\mathrm{AT}_{1} \mathrm{R}$, Woods et al. demonstrated that $\mathrm{AT}_{1} \mathrm{R}$ played a key role in fetal programming of aberrant renal development and hypertension in offspring ${ }^{9}$. In the present study, we demonstrated that fetal hypoxia did not affect the expression of $\mathrm{AT}_{1} \mathrm{R}$ in E21 and $\mathrm{P7}$ rats, but significantly decreased $\mathrm{AT}_{1} \mathrm{R}$ expression in adult offspring. Additionally, this effect is more pronounced in females than males. This is consistent with the finding of the greater reduction in nephron numbers in female than male adult offspring and suggests that the decreased $\mathrm{AT}_{1} \mathrm{R}$ in adult kidneys is due to reduced nephron numbers in hypoxic-treated animals. This finding raises the possibility of a sex-dependent effect due to maternal hypoxia on the renal $\mathrm{AT}_{1} \mathrm{R}$ expression may lead to sex differences on the impact of maternal hypoxia on adult disease. The finding that $\mathrm{AT}_{2} \mathrm{R}$ in the kidney was not significantly affected by fetal hypoxia in all the developmental ages examined in the present study suggests a predomi- nate location of $\mathrm{AT}_{2} \mathrm{R}$ in extra-nephron tissues in the kidney. Indeed, Miyata et al. ${ }^{29}$ demonstrated that $\mathrm{AT}_{1} \mathrm{R}$, but not $\mathrm{AT}_{2} \mathrm{R}$, mRNA was detected in the nephron. $\mathrm{AT}_{1} \mathrm{R}$ and $\mathrm{AT}_{2} \mathrm{R}$ have different function and imbalance of $\mathrm{AT}_{1} \mathrm{R}$ and $\mathrm{AT}_{2} \mathrm{R}$ expression and activity contributes to various kidney disorders ${ }^{30}$. Although the present finding of antenatal hypoxia-induced reduction of $A T_{1} R / A T_{2} R$ expression ratio in the kidney of adult offspring is likely to have a significant effect on the renal function, the expression of $\mathrm{AT}_{1} \mathrm{R}$ and $\mathrm{AT}_{2} \mathrm{R}$ alone may not be a measure of total RAS-mediated function in the kidney. Future studies are needed to investigate the effect of hypoxia on other RAS components as well as the post receptor signaling, which are also involved in the kidney function.

Although $\mathrm{AT}_{1} \mathrm{R}$ plays an important role in normal kidney development ${ }^{31}$, fetal hypoxia had no effect on $\mathrm{AT}_{1} \mathrm{R}$ in the kidney but decreased nephron numbers in P7 rats, suggesting other mechanisms may be involved in the hypoxia-mediated abnormal nephron development. Possible mechanisms include Wnt4 that is required by the metanephric mesenchyme for differentiation into nephron epithelia ${ }^{32}$, or fibroblast growth factor-2 33 and transforming growth factor $\beta-2{ }^{34}$ that are capable of inducing nephrons. Another possible mechanism is that hypoxia may affect the expression of retinoid receptors that mediate remodeling process in epithelial cells associated with nephron genesis ${ }^{35}$. Additionally, it has been shown that hypoxia increases the expression of glucocorticoid receptors in the primary human renal cortex epithelial cells ${ }^{36}$, and that glucocorticoids play an important role in accelerating the maturation process of the kidney function 37,38 . Furthermore, the previous study demonstrated that hypoxia up-regulated the expression of angiopoietin-2 in cultured mouse kidney mesangial cells, which may have a synergistic paracrine role in the growth of glomerular endothelial during the development of the kidney ${ }^{39}$. In humans, it has been shown that the aging process of the kidney induces changes in anatomic and function of the renal system, including reduction of glomerular filtration rate (GFR), segmental glomerular sclerosis, reduction in the number of glomeruli and a decrease in renal mass ${ }^{40}$. These changes may result in chronic kidney diseases (CKD) a risk factor that eventually induced cardiac complications. Our results suggest that fetal hypoxia induces aberrant nephrogenesis and accelerates the aging process of the kidney. Additionally, the results suggest that the mechanisms other than the renal RAS may be involved in fetal hypoxia-mediated programming of abnormal kidney development. Future studies are required to further elucidate these 
unknown pathways.

\section{Acknowledgement}

This work was supported by National Institutes of Health Grants HL83966 and 5 P20 MD001632.

\section{Conflicting Interests}

The authors declared no conflicts of interest with respect to the authorship and/or publication of this article.

\section{References}

1. Barker DJ. Fetal origins of coronary heart disease. Bmj. 1995; 311(6998):171-174.

2. Barker DJ. The fetal origins of coronary heart disease. Eur Heart J. 1997;18(6): 883-884.

3. Woods LL, Ingelfinger JR, Nyengaard JR, Rasch R. Maternal protein restriction suppresses the newborn renin-angiotensin system and programs adult hypertension in rats. Pediatr Res. 2001;49(4): 460-467.

4. Lawrence J, Xiao D, Xue Q, Rejali M, Yang S, Zhang L. Prenatal nicotine exposure increases heart susceptibility to ischemia/reperfusion injury in adult offspring. J Pharmacol Exp Ther. 2008;324(1): 331-341.

5. Zhang DY, Lumbers ER, Simonetta G, et al. Effects of placental insufficiency on the ovine fetal renin-angiotensin system. Exp Physiol. 2000;85(1): 79-84.

6. Julian CG, Vargas E, Armaza JF, Wilson MJ, Niermeyer S, Moore LG. High-altitude ancestry protects against hypoxia-associated reductions in fetal growth. Arch Dis Child Fetal Neonatal Ed. 2007;92(5):F372-377.

7. Brenner BM, Chertow GM. Congenital oligonephropathy and the etiology of adult hypertension and progressive renal injury. Am J Kidney Dis. 1994;23(2):171-175.

8. Larsson L, Aperia A, Wilton P. Effect of normal development on compensatory renal growth. Kidney Int. 1980;18(1): 29-35.

9. Woods LL, Rasch R. Perinatal ANG II programs adult blood pressure, glomerular number, and renal function in rats. Am J Physiol. 1998;275(5 Pt 2): R1593-1599.

10. Weinstein JR, Anderson S. The aging kidney: physiological changes. Adv Chronic Kidney Dis. 2010;17(4):302-307.

11. Tufro-McReddie A, Romano LM, Harris JM, Ferder L, Gomez RA. Angiotensin II regulates nephrogenesis and renal vascular development. Am J Physiol. 1995;269(1 Pt 2):F110-115.

12. de Gasparo M, Catt KJ, Inagami T, Wright JW, Unger T. International union of pharmacology. XXIII. The angiotensin II receptors. Pharmacol Rev. 2000;52(3):415-472

13. Li G, Xiao Y, Estrella JL, Ducsay CA, Gilbert RD, Zhang L. Effect of fetal hypoxia on heart susceptibility to ischemia and reperfusion injury in the adult rat. J Soc Gynecol Investig. 2003;10(5):265-274.

14. Mao C, Hou J, Ge J, et al. Changes of renal AT1/AT2 receptors and structures in ovine fetuses following exposure to long-term hypoxia. Am J Nephrol. 2010;31(2): 141-150.

15. Boubred F, Buffat C, Feuerstein JM, et al. Effects of early postnatal hypernutrition on nephron number and long-term renal function and structure in rats. Am J Physiol Renal Physiol. 2007;293(6):F1944-1949.

16. Eriksson JG, Forsen T, Tuomilehto J, Winter PD, Osmond C, Barker DJ. Catch-up growth in childhood and death from coronary heart disease: longitudinal study. Bmj. 1999;318(7181): 427-431.

17. Tapanainen PJ, Bang P, Wilson K, Unterman TG, Vreman HJ, Rosenfeld RG. Maternal hypoxia as a model for intrauterine growth retardation: effects on insulin-like growth factors and their binding proteins. Pediatr Res. 1994;36(2):152-158.

18. Chen JH, Martin-Gronert MS, Tarry-Adkins J, Ozanne SE. Maternal protein restriction affects postnatal growth and the expression of key proteins involved in lifespan regulation in mice. PLoS One. 2009;4(3): e4950.

19. Woods LL, Weeks DA, Rasch R. Programming of adult blood pressure by maternal protein restriction: role of nephrogenesis. Kidney Int. 2004;65(4):1339-1348.

20. Woods LL, Ingelfinger JR, Rasch R. Modest maternal protein restriction fails to program adult hypertension in female rats. Am J Physiol Regul Integr Comp Physiol. 2005;289(4): R1131-1136.
21. Mao $\mathrm{C}, \mathrm{Wu} \mathrm{J}, \mathrm{Xiao} \mathrm{D}$, et al. The effect of fetal and neonatal nicotine exposure on renal development of $\mathrm{AT}(1)$ and $\mathrm{AT}(2)$ receptors. Reprod Toxicol. 2009;27(2):149-154.

22. Luzi G, Bori S, Iammarino G, et al. [Functional aspects of the fetal urinary apparatus in relation to growth]. Arch Ital Urol Androl. 1996;68(5 Suppl): 9-12.

23. Brenner BM, Garcia DL, Anderson S. Glomeruli and blood pressure. Less of one, more the other? Am J Hypertens. 1988;1(4 Pt 1):335-347.

24. Keller G, Zimmer G, Mall G, Ritz E, Amann K. Nephron number in patients with primary hypertension. N Engl J Med. 2003;348(2):101-108.

25. Gray SP, Denton KM, Cullen-McEwen L, Bertram JF, Moritz KM. Prenatal exposure to alcohol reduces nephron number and raises blood pressure in progeny. J Am Soc Nephrol. 2010;21(11): 1891-1902.

26. Hoy WE, Bertram JF, Denton RD, Zimanyi M, Samuel T, Hughson MD. Nephron number, glomerular volume, renal disease and hypertension. Curr Opin Nephrol Hypertens. 2008;17(3): 258-265.

27. Hostetter TH. Hyperfiltration and glomerulosclerosis. Semin Nephrol. 2003;23(2): 194-199.

28. Kobori H, Ozawa Y, Suzaki Y, et al. Young Scholars Award Lecture: Intratubular angiotensinogen in hypertension and kidney diseases. Am J Hypertens. 2006;19(5):541-550.

29. Miyata N, Park F, Li XF, Cowley AW, Jr. Distribution of angiotensin AT1 and AT2 receptor subtypes in the rat kidney. Am J Physiol. 1999;277(3 Pt 2): F437-446.

30. Lai KN, Chan LY, Tang SC, et al. Mesangial expression of angiotensin II receptor in IgA nephropathy and its regulation by polymeric IgA1. Kidney Int. 2004;66(4):1403-1416.

31. Oliverio MI, Kim HS, Ito M, et al. Reduced growth, abnormal kidney structure, and type 2 (AT2) angiotensin receptor-mediated blood pressure regulation in mice lacking both AT1A and AT1B receptors for angiotensin II. Proc Natl Acad Sci U S A. 1998;95(26):15496-15501.

32. Stark K, Vainio S, Vassileva G, McMahon AP. Epithelial transformation of metanephric mesenchyme in the developing kidney regulated by Wnt-4. Nature. 1994;372(6507): 679-683.

33. Karavanova ID, Dove LF, Resau JH, Perantoni AO. Conditioned medium from a rat ureteric bud cell line in combination with bFGF induces complete differentiation of isolated metanephric mesenchyme. Development. 1996;122(12):4159-4167.

34. Sanford LP, Ormsby I, Gittenberger-de Groot AC, et al. TGFbeta2 knockout mice have multiple developmental defects that are non-overlapping with other TGFbeta knockout phenotypes. Development. 1997;124(13):2659-2670.

35. Batourina E, Gim S, Bello N, et al. Vitamin A controls epithelial/mesenchymal interactions through Ret expression. Nat Genet. 2001;27(1):74-78.

36. Jenq W, Rabb H, Wahe M, Ramirez G. Hypoxic effects on the expression of mineralocorticoid and glucocorticoid receptors in human renal cortex epithelial cells. Biochem Biophys Res Commun. 1996;218(2):444-448.

37. Petershack JA, Nagaraja SC, Guillery EN. Role of glucocorticoids in the maturation of renal cortical Na+-K+-ATPase during fetal life in sheep. Am J Physiol. 1999;276(6 Pt 2): R1825-1832.

38. Seckl JR. Prenatal glucocorticoids and long-term programming. Eur J Endocrinol. 2004;151: U49-62.

39. Yuan HT, Yang SP, Woolf AS. Hypoxia up-regulates angiopoietin-2, a Tie-2 ligand, in mouse mesangial cells. Kidney Int. 2000;58(5): 1912-1919.

40. Epstein M. Aging and the kidney. J Am Soc Nephrol. 1996;7(8): 1106-1122. 